\title{
O uso de fontes de informação nacionais e internacionais: uma pesquisa nos portais Superinteressante e Galileu
}

\author{
Gabriella Zauith Leite Lopes ${ }^{1}$ \\ Giovana Alves Faria ${ }^{2}$
}

\section{Resumo}

Este artigo traz dados da pesquisa quantitativa que avalia a noticiabilidade da informação científica em matérias de portais de revistas de divulgação científica brasileiras. O estudo considerou o uso de fontes de informação internacionais e nacionais. O corpus de análise totalizou uma amostra com 730 matérias das editorias de Saúde e Ciência veiculadas em dois períodos diferentes nas edições online das revistas Superinteressante e Galileu. A primeira fase fez parte do projeto de Iniciação Científica (PIC), em 2016, com coleta na editoria de Saúde e a segunda foi tema do TCC, concluído em 2018, na editoria de Ciências. A maioria das fontes de informação utilizadas nas matérias de ambos os portais são provenientes de entidades e revistas científicas internacionais renomadas. Resultados parciais apontam a subutilização de fontes nacionais, provenientes da pesquisa científica nacional.

Palavras-chave: Jornalismo científico. Revistas de divulgação científica. Noticiablidade. Fontes de Informação.

\section{Abstract}

This article brings data from the quantitative research that evaluates the newsworthiness of scientific information on the subject of portals of Brazilian scientific popularization magazines. The study considered the use of international and national sources of information. The corpus of analysis totaled a sample of 730 articles from the Health and Science publishers published in two different periods in the online editions of Superinteressante and Galileo magazines. The first phase was part of the Scientific Initiation Project (PIC), in 2016, with collection in the Health editor and the second was the subject of the TCC, completed in 2018, in the science editor. Most of the information sources used in the materials of both portals come

\footnotetext{
1 Doutora em Educação e mestre em Ciência, Tecnologia e Sociedade pela UFScar (Universidade Federal de São Carlos). Graduação em Jornalismo (Unaerp) e Pedagogia (Unigran). Professora do curso de Jornalismo no Centro Universitário Barão de Mauá, em Ribeirão Preto (SP). E-mail: gabi_z@live.com.

2 Formada em Jornalismo pelo Centro Universitário Barão de Mauá. Bolsista do Future News Worldwide em Edimburgo, Escócia. Realizou intercâmbio acadêmico na Universidade do Porto, Portugal. E-mail: giovana.farial@outlook.com.
}

Revista Pauta Geral-Estudos em Jornalismo, Ponta Grossa, vol. 6, n. 1, p. 148-165, Jan/Jun, 2019. 
from renowned international scientific entities and journals. Partial results indicate the underutilization of national sources, derived from national scientific research.

Keywords: Scientific journalism. Scientific dissemination magazines. Information sources.

\section{Introdução}

A crescente popularidade da internet como um canal de informação fez com que o acesso às publicações impressas reduzisse substancialmente por parte dos cidadãos. Em muitos lugares nos Estados Unidos foram até mesmo reduzidas as frequências de publicação, além do grande número de funcionários dispensados. Os números do Bureau of Labor Statistics do Departamento de Trabalho dos EUA indicam que a indústria de jornais como um todo declinou 40\% ao longo de uma década no país (ZARA, 2013 apud BUCCHI; TRENCH, 2014).

A internet ganhou uma proporção tão grande e assumiu um papel importante na sociedade do século $\mathrm{XXI}$, servindo até mesmo como fonte de informação para esses jornalistas que estão migrando para o meio virtual. Esses jornalistas que estão começando a atuar nas mídias digitais possuem uma responsabilidade gigante com relação ao uso de fontes provenientes do ciberespaço. Como diz Machado (2003), existe agora uma multiplicação de fontes sem tradição especializada no tratamento de notícias espalhadas em escala mundial pela rede. Ou seja, fica mais complicado atuar da mesma maneira que um jornalista de um sistema convencional de comunicação atuava, dando preferência às fontes oficiais. Algo que também não pode ser definido como critério único, pois arrisca a credibilidade da publicação pelo tom oficialista dos conteúdos. Estando sujeito a tantas fontes e a informações de dezenas de lugares, o trabalho de apuração no ciberespaço deve ser feito com o dobro de cautela que já utilizam os jornalistas convencionais, pois todos os indivíduos possuem a liberdade e o poder de se tornarem fontes na internet.

A novidade do jornalismo digital reside no fato de que, quando fixa um entorno de arquitetura descentralizada, altera a relação de forças entre os diversos tipos de fontes porque concede a todos os usuários o status de fontes potenciais para os jornalistas. Se cada indivíduo ou instituição, desde que munido das condições técnicas adequadas, pode inserir conteúdos no ciberespaço devido a facilidade de domínio de áreas cada vez mais vastas, fica evidenciada tanto uma certa diluição do papel do jornalista como único intermediário para filtrar as mensagens autorizadas a entrar na esfera pública, quanto das fontes profissionais detentoras do quase monopólio do acesso aos jornalistas. A possibilidade de dispensa

Revista Pauta Geral-Estudos em Jornalismo, Ponta Grossa, vol. 6, n. 1, p. 148-165, Jan/Jun, 2019. 
de intermediários entre as fontes e usuários implode com a lógica do predomínio das fontes profissionais porque transforma os próprios usuários em fontes não menos importantes (MACHADO, 2003, p. 6).

\section{O jornalista científico do século XXI}

Frente a uma gama de possibilidades em que os jornalistas enfrentam em busca de fontes de informações, o jornalismo científico também se encontra nesse desafio. Em alguns países, esses profissionais se sentem em apuros com as novas mídias, enquanto em outros eles continuam a prosperar e a ocupação continua a crescer. Dados sistemáticos são difíceis de encontrar, mas contas anedóticas sugerem que jornalistas científicos nos EUA se encontram por conta própria, nas filas de freelancers, já que suas antigas organizações de mídia reduziram (BRUMFIEL, 2009 apud BUCCHI; TRENCH, 2014).

Todas as editorias de um veículo de comunicação necessitam de grande apuração e cuidado na produção, mas editorias como as de economia, política e ciência, por exemplo, merecem atenção redobrada. Estas exercem grande influência no nosso dia a dia, e por cada uma delas utilizarem jargões específicos e complexos, cabe ao jornalista a tradução e transmissão de maneira clara do conteúdo correspondente a essas áreas para o grande público.

Com a intenção de compreender melhor esse cenário, o presente artigo aponta na direção do compromisso do jornalista com a apuração, e com o uso coerente de fontes relacionadas às editorias de saúde e ciência. O objetivo foi analisar o uso de fontes nacionais e internacionais em matérias das edições online das revistas Superinteressante e Galileu. O critério de seleção foi utilizar as revistas de divulgação científica de maior circulação no mercado e com plataformas de conteúdo online. Além da identificação das fontes de informação, relacionadas à sites e revistas utilizadas, a pesquisa descreveu temas mais abordados agrupados em categorias, e a autoria das matérias.

O corpus de análise incluiu resultados de duas coletas de dados realizadas em períodos distintos. $\mathrm{Na}$ amostra foram analisadas 730 matérias das editorias de Saúde e Ciência veiculadas em dois períodos diferentes nas edições online das revistas Superinteressante e Galileu. As coletas foram realizadas respectivamente no Projeto de Iniciação Científica, em 2015, com o trabalho: Fontes de informação em notícias de saúde: uma busca em portais de revistas de Divulgação Científica (FARIA; ZAUITH, 2016). Posteriormente, em 2018, a investigação foi estendida no Trabalho de Conclusão de Curso 
com o tema: A pesquisa internacional como fonte de notícias de ciência: uma busca em portais de revistas de divulgação científica (FARIA; ZAUITH, 2018).

No primeiro momento, foram coletadas 65 publicações de ambos os portais das revistas na editoria de saúde, $87,69 \%$ das matérias são provenientes de pesquisas internacionais, $10,76 \%$ nacionais e $1,53 \%$ mistas. Um resultado obtido no período apurado foram as notícias sobre a "pílula do câncer", considerada uma fraude posteriormente. Para o projeto de conclusão de curso, foram coletadas 655 publicações de ambos os portais das revistas na editoria de ciência. Com relação à origem de fontes, $84 \%$ das matérias são provenientes de pesquisas internacionais, $10 \%$ nacionais e $4 \%$ mistas.

A pesquisa é denominada quantitativa e os procedimentos incluem pesquisa bibliográfica e documental (GIL, 2002). A análise foi realizada em quatro etapas incluindo a seleção e coleta de dados, análise por categorias temáticas e articulação com material coletado por cada site. Os dados foram catalogados numa tabela Excel contendo os seguintes campos: veículo; editoria; data; autor; título da matéria; tema; fontes e link de fontes.

\section{Jornalismo e Divulgação científica}

O jornalismo científico pode ser definido como o instrumento mais eficaz de popularização do conhecimento científico, possibilitando sua apropriação pela sociedade e servindo de ferramenta de educação para a ciência. $O$ jornalismo científico pode ter um caráter informativo como notas, notícias, reportagens, entrevistas e um caráter opinativo nos editoriais, comentários, artigos, colunas, crônicas, cartoons e cartas (ALBAGLI, 1996).

Apesar de exercer a função de divulgar a ciência à sociedade, existe uma diferença entre jornalismo científico e divulgação científica. Esta última pode ser descrita como "a tradução de uma linguagem especializada para uma leiga, visando a atingir um público mais amplo" (ALBAGLI, 1996, p. 397).

Bueno (2010) também ressalta a diferença dos públicos de comunicação e divulgação científica.

O público difere, fundamentalmente, nos processos de comunicação e de divulgação científica. No primeiro caso, está identificado com os especialistas, ou seja, pessoas que, por sua formação específica, estão familiarizadas com os temas, os conceitos e o próprio processo de produção em ciência e tecnologia (C\&T). No segundo caso - divulgação científica ele é, prioritariamente, um não iniciado, quer dizer, não tem, 
obrigatoriamente, formação técnico-científica que Ihe permita, sem maior esforço, decodificar um jargão técnico ou compreender conceitos que respaldam o processo singular de circulação de informações especializadas (BUENO, 2010, p.2).

Segundo Oliveira (2005), a população brasileira tem interesse em assuntos relacionados à ciência e tecnologia. A ciência é uma área do conhecimento do qual dependemos para a realização de pesquisas relacionadas à área da saúde como o desenvolvimento de novos medicamentos, tratamento e prevenção de doenças e evoluções tecnológicas facilitadoras do nosso cotidiano.

No Brasil, a prática do jornalismo científico foi tardia. Enquanto na Europa e nos Estados Unidos já estava a todo vapor no século XIX, no Brasil foi apenas no início deste século que a proibição de impressão de livros e jornais foi suspensa pela corte portuguesa (OLIVEIRA, 2005).

Em meados da década de 1940 a ciência brasileira finalmente entrou na agenda do governo e da sociedade. O primeiro marco deste acontecimento foi a criação da Sociedade Brasileira para o Progresso da Ciência (SBPC) em 1948, entidade que hoje congrega todas as sociedades científicas do país. O segundo marco foi a criação do Conselho Nacional de Pesquisas, CNPq, em janeiro de 1951 e três décadas depois, a criação do Ministério da Ciência e Tecnologia (MCT).

A partir da década de 1980 este quadro de disparidade começou a ser revertido. A divulgação e o jornalismo científico no Brasil cresceram significativamente com o surgimento de novas revistas como Ciência Hoje (SBPC) e Ciência llustrada (Editora Abril). Em 1990, a Editora Globo lançou a revista Globo Ciência (atual Galileu) e, no mesmo ano, a Editora Abril lançou a Superinteressante (OLIVEIRA, 2005).

Após anos de defasagem, atualmente a produção da pesquisa científica nacional está em primeiro lugar na América Latina e em 23ํㅡ no ranking global (NATURE INDEX, 2018). De acordo com informações contidas do banco de dados do SCImago Journal \& Country Rank (2016), só em 2016 foram 68.908 artigos publicados no Brasil, sendo as áreas de maior evidência com relação ao número de publicações: a Medicina, com 18.247 estudos publicados; Agricultura e Ciências Biológicas com 13.780 artigos e Engenharia com 8.315 publicações. Mesmo com o avanço, a literatura nacional sobre jornalismo científico disponível ainda é escassa, estando mais presente em artigos científicos. 


\section{Resultados e discussões}

Na primeira etapa da pesquisa quantitativa (GIL, 2002), ocorrida em março e abril de 2016, foram coletadas 65 publicações de ambos os portais on-line das revistas, nos quais 15 (23,07\%) das matérias são de autoria da revista Galileu e 50 (76,92\%) da revista Superinteressante.

Considerando os dois veículos de informação, 87,69\% das matérias são provenientes de pesquisas internacionais, $10,76 \%$ nacionais e $1,53 \%$ mistas, ou seja, oriundas de parceria entre duas ou mais universidades brasileiras e estrangeiras (Gráfico 1).

\section{Gráfico 1: Origem das Fontes}

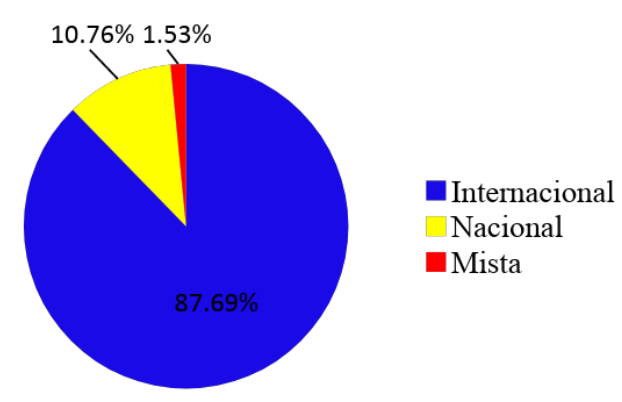

Das pesquisas internacionais utilizadas como fontes, 12 são provenientes de outros sites, sendo estes Journal of Medicinal Chemistry, Fitness Magazine, Fast Coexist EXAME, BioViva, SpectraCell, Nasa, Bored Panda, Technology Review, G1, Oxford Academic Journals e Journal Plos. E 20 citam pelo menos um responsável pela pesquisa, e 26 citam somente a universidade ou instituição responsável pela pesquisa (Gráfico 2).

Gráfico 2: Caracterização das Fontes 


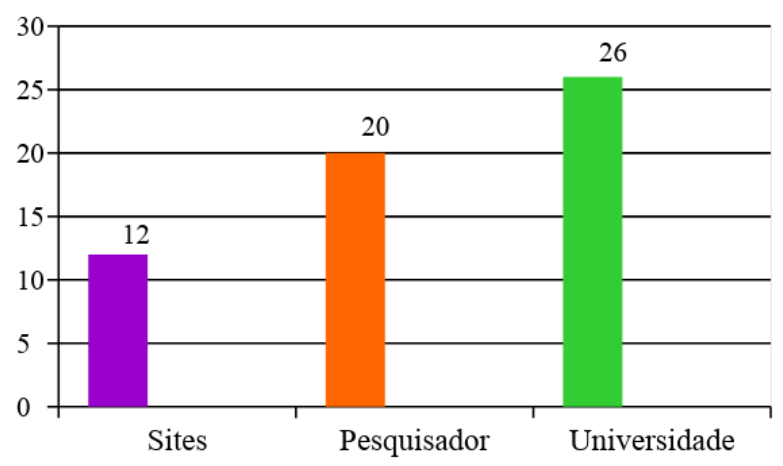

Dentre as categorias agrupadas, as mais citadas foram psicologia $(21,53 \%)$, nutrição (13,84\%), genética (10,76\%), câncer (7,69\%), biotecnologia e medicamentos (6,15\%) (Gráfico 3).

Gráfico 3: Categoria das Matérias
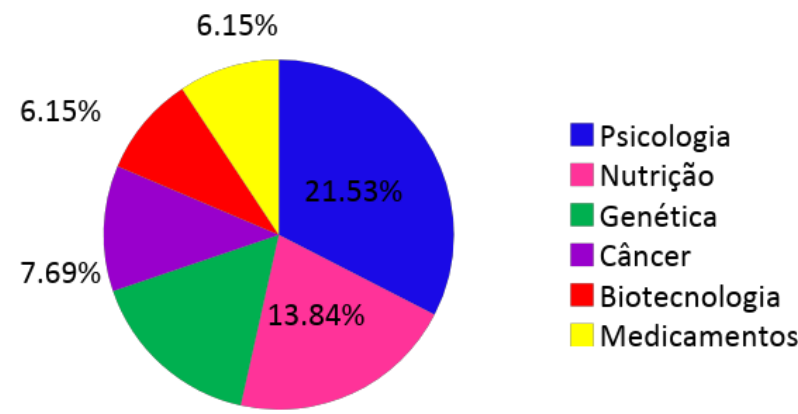

$10.76 \%$

Dentre as categorias, a matéria "Quanto tempo levaria para um vampiro tomar seu sangue?" proveniente da revista Superinteressante, foi a única classificada como Pseudociência, que, de acordo com a definição do Oxford Dictionaries é "uma coleção de crenças ou práticas consideradas equivocadamente como baseadas no método científico".

Nas matérias de psicologia, os temas abordados foram sono e comportamento ( 3 matérias de cada), depressão, memória, uso de drogas e aprendizagem (2). Na categoria de nutrição, os temas foram em sua maioria dietas (6) e as demais sobre veganismo, genética, alimentação e obesidade infantil. Na categoria de genética os temas incluíram envelhecimento (2), doenças (2), comportamento e gêmeos. 
Dentre os autores das matérias assinadas, foram identificados 18 jornalistas na Revista Superinteressante e três na Galileu. Dentre os que mais produziram conteúdo na revista Superinteressante estão Helô D'Angelo (13 matérias), Pâmela Carbonari (9) e Felipe Germano (6). A revista também publicou conteúdo da revista Exame, dos jornalistas Nicolas Gunkel, Marina Demartini e Daniela Barbosa, bem como do portal HuffPost Brasil. Na Galileu, foram Lucas Alencar (11 matérias), e Cláudia Fusco e Isabela Moreira, ambas com duas matérias.

Helô D'Angelo é formada em Jornalismo pela Faculdade de Comunicação Social Cásper Líbero e na ocasião estagiária na revista Superinteressante. Pâmela Carbonari é formada em Jornalismo pela Universidade Federal de Santa Catarina e repórter na revista Superinteressante e Felipe Germano é formado em Jornalismo pela Universidade Presbiteriana Mackenzie e jornalista na revista Superinteressante.

Quanto aos jornalistas da revista Galileu, Lucas Alencar é formado em Jornalismo pela Universidade Metodista de São Paulo e repórter estagiário, Cláudia Fusco e Isabela Moreira são formadas em jornalismo pela Faculdade de Comunicação Social Cásper Líbero, Cláudia Fusco é editora on-line e Isabela Moreira é repórter na revista Galileu.

\section{Fosfoetanolamina e a divergência das informações}

Com relação às sete matérias com fontes de informações de origem nacional $(10,76 \%)$, das duas revistas, quatro tinham como assunto principal a fosfoetanolamina, sendo três delas publicadas pela revista Superinteressante (Quadro 1).

Quadro 1: Matérias coletadas sobre fosfoetanolamina

\begin{tabular}{|l|l|l|l|}
\hline \multicolumn{1}{|c|}{ Título da matéria } & Data & Revista & Autoria \\
\hline $\begin{array}{l}\text { Câmara autoriza pílula do câncer } \\
\text { mesmo sem registro da Anvisa }\end{array}$ & $9 /$ março/16 & Superinteressante & Pâmela Carbonari \\
\hline Dilma legaliza a pílula do câncer & $14 /$ março/16 & Superinteressante & Helô D’Angelo \\
\hline $\begin{array}{l}\text { Senado aprova uso de substância } \\
\text { sem eficácia comprovada contra o } \\
\text { câncer }\end{array}$ & $23 /$ março/16 & Galileu & $\begin{array}{l}\text { Lucas Alencar com } \\
\text { supervisão de Cláudia } \\
\text { Fusco }\end{array}$ \\
\hline
\end{tabular}

Revista Pauta Geral-Estudos em Jornalismo, Ponta Grossa, vol. 6, n. 1, p. 148-165, Jan/Jun, 2019. 
A primeira matéria sobre o tema, publicada pela Superinteressante, no dia 9 de março de 2016 trazia a informação de que a Câmara dos Deputados havia autorizado a produção e o uso da fosfoetanolamina sintética, antes mesmo da Anvisa dar o aval de eficácia e segurança para o registro como medicamento. Na segunda matéria, publicada cinco dias depois também pela Superinteressante, a "pílula do câncer" já havia sido aprovada pela presidente da época, Dilma Rousseff. Dia 28 de março a Superinteressante publicou a última matéria abordando o tema, trazia a informação de que a "pílula anticâncer" desenvolvida na USP estava sendo criticada pela Unicamp. A única matéria nacional publicada pela Galileu no dia 23 de março trazia a informação da aprovação do uso da substância pelo Senado mesmo sem eficácia comprovada.

Analisando notícias atuais deste tema, dois anos depois (2018) do ano em que essa pesquisa foi realizada, foram encontradas duas notícias atualizadas em outubro de 2016, na Superinteressante, trazendo fatos que contestam a credibilidade da "pílula do câncer". $\mathrm{Na}$ Galileu não consta nenhuma notícia posterior contendo a atualização do fato (Quadro 2).

Quadro 2: Matérias coletadas sobre fosfoetanolamina, após sete meses

\begin{tabular}{|l|l|l|l|}
\hline Título da matéria & Data & Revista & Autoria \\
\hline $\begin{array}{l}\text { A polêmica da droga anticâncer: USP afirma } \\
\text { que fosfoetanolamina não é remédio }\end{array}$ & out/2016 & Superinteressante & $\begin{array}{l}\text { Ana } \\
\text { Fernandes }\end{array}$ \\
\hline $\begin{array}{l}\text { "Cientistas decidem frear testes com a "pílula } \\
\text { do câncer }\end{array}$ & abril/2017 & Superinteressante & Theo Ruprecht \\
\hline
\end{tabular}

Uma matéria do dia 31 de outubro de 2016, da Superinteressante, "A polêmica da droga anticâncer: USP afirma que fosfoetanolamina não é remédio", de Ana Luísa Fernandes, trazem declarações oficiais da USP dizendo que "a substância é produzida de forma artesanal e que não foi devidamente testada", e ainda um comunicado da Anvisa que 
confessa que "não há na Anvisa qualquer registro concedido ou pedido de registro para medicamentos com o princípio ativo fosfoetanolamina".

Em abril de 2017, uma nova matéria da Superinteressante, "Cientistas decidem frear testes com a "pílula do câncer"', de Theo Ruprecht, apresenta resultados de uma pesquisa realizada com pacientes com dez tipos diferentes de tumores. Dos 59 voluntários, apenas um obteve resposta significativa. Por esse motivo, o estudo conduzido no Instituto do Câncer do Estado de São Paulo (Icesp) foi suspenso.

\section{Segunda etapa}

A segunda fase da pesquisa foi mais abrangente, e durou quatro meses (janeiro, fevereiro, março e abril de 2018) com 655 matérias de ambos os portais, sendo 431 (65,8\%) de autoria da Galileu e 224 (34,1\%) da Superinteressante. Foram, ao todo, 552 (84,27\%) matérias que utilizaram fontes de informação de origem internacional ao longo dos quatro meses de análise e 67 (10,22\%) de origem nacional.

Analisando as fontes de informação (Gráfico 4), os sites que mais foram utilizados para a obtenção de conteúdo para produção das notícias foram, respectivamente, o portal da Nature 60 (9,16\%), Nasa 43 (6,56\%), IFL Science 28 (4,27\%), Science 26 (3,96\%), Science Alert 17 (2,59\%), Eureka Alert 13 (1,98\%) e o Science Daily 7 (1,06\%).

As revistas Nature e Science, duas das mais consagradas revistas científicas, possuem portais online onde é possível acessar artigos científicos de pesquisas de qualquer universidade e entidade do mundo, tornando-se assim algumas das fontes favoritas dos jornalistas de ciência.

Tendo em vista o fato de que a Nasa é a agência líder em pesquisa e desenvolvimento e programas de exploração espacial, com notícias relacionadas à astronomia, engenharia espacial e tecnologia espacial, a maioria das matérias desta área são oriundas do site da Nasa.

Sites como o IFL Science, Science Alert, Science Daily e Eureka Alert são sites de notícias científicas que abordam temáticas que vão desde tecnologia, meio ambiente, astronomia, saúde, medicina, física e química.

Gráfico 4: Análise das fontes nos sites das revistas Galileu e Superinteressante 


\section{ESTUDOS EM JORNALISMO}

10.5212/RevistaPautaGeral.v6.i1.0009

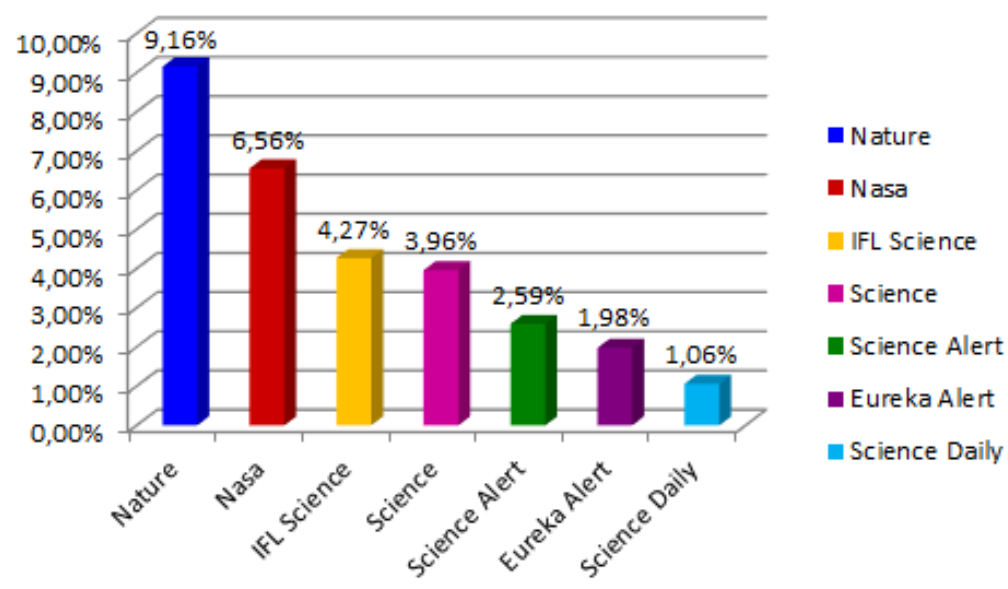

A maioria das matérias, 341 (59\%), citou o nome de pelo menos um pesquisador responsável pela pesquisa, enquanto 237 (41\%) notícias citaram pelo menos o nome da entidade responsável pela pesquisa (Gráfico 5).

Gráfico 5: Entidades e pesquisadores dos portais Galileu e Super

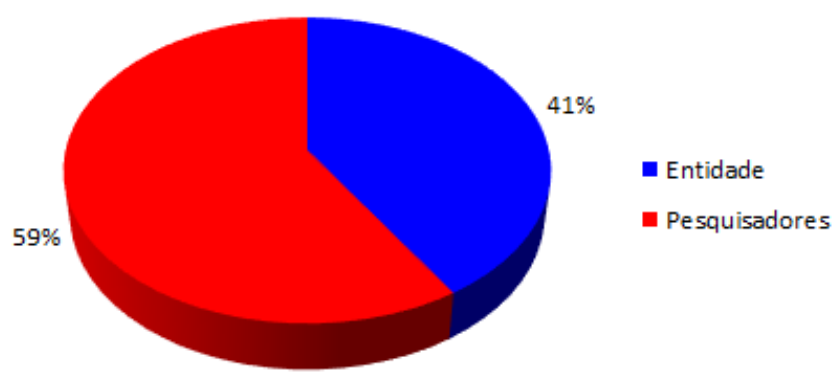

Durante os quatro meses, em ambos os portais, os temas que mais se destacaram foram astronomia (139), zoologia (81), arqueologia (58) e saúde (57) (Gráfico 6).

Gráfico 6: Temas abordados durante os quatro meses em ambos os portais 


\section{ESTUDOS EM JORNALISMO}

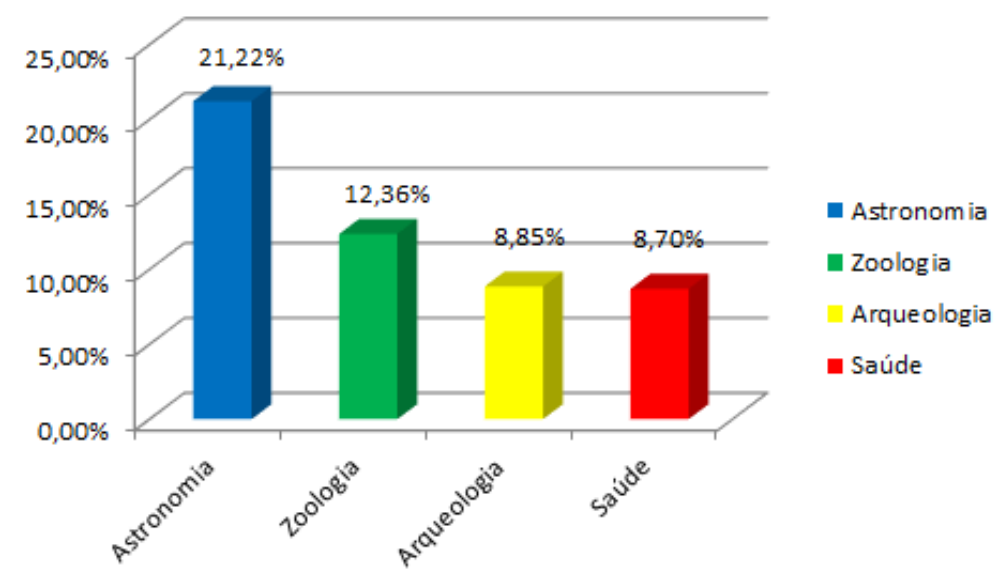

\section{Lute pela ciência}

Como destaque para o mês de março que teve, pela Galileu, duas hashtags personalizadas: \#lutepelaciencia e Stephen Hawking. A hashtag "lute pela ciência" foi utilizada para identificar as matérias que traziam conteúdos referentes ao financiamento da pesquisa brasileira. Três matérias foram produzidas neste mês com essa temática, sendo duas de autoria de Felipe Floresti e uma da Redação Galileu.

As duas primeiras, intituladas respectivamente "Proposta do MCTIC para a Antártica é "um desaforo", afirma pesquisador" e "Sem dinheiro, Brasil corre risco de ficar sem cientistas na Antártida", relata a baixa verba disponibilizada pelo Ministério da Ciência, Tecnologia, Inovação e Comunicações (MCTIC) para o Programa Antártico Brasileiro. A terceira, "Por falta de pagamento, Brasil é suspenso do Observatório Europeu do Sul" traz a notícia de que, o Brasil foi suspenso do Observatório Europeu do Sul (ESO), pois não chegou nem a finalizar o processo que o nomearia como um dos Estados-membros, que se tratava do pagamento de $R \$ 1$ bilhão em parcelas até o ano 2021.

Devido à morte do físico britânico Stephen Hawking, um dos cientistas mais consagrados do século, em março, matérias começaram a ser produzidas relembrando o legado deixado pelo físico, fatos curiosos sobre sua vida, entre outros. Por este acontecimento ter causado grande repercussão para a ciência mundial, ambos os portais passaram a identificar suas matérias relacionadas a ele com a hashtag Stephen Hawking. A Superinteressante publicou quatro matérias sobre Stephen Hawking, enquanto a Galileu publicou sete. 


\section{Origem das Fontes}

Foi possível observar que a maioria das matérias nos portais da Galileu e da Superinteressante, durante todos os quatro meses de coleta de dados, possuem fontes de origem internacional. Foram, ao todo, 552 (84,27\%) matérias de origem internacional ao longo dos quatro meses de análise contra 67 (10,22\%) de origem nacional. Abaixo estão descritas as fontes utilizadas em cada mês.

O mês de janeiro (Gráfico 7) trouxe 118 (18,01\%) matérias de origem internacional, $17(2,59 \%)$ de origem nacionais, $7(1,06 \%)$ mistas, ou seja, pesquisas oriundas de parcerias entre universidades e ou pesquisadores brasileiros e estrangeiros, e duas $(0,30 \%)$ matérias não identificaram a origem das fontes utilizadas. Das notícias nacionais, 14 têm como fonte pelo menos um pesquisador responsável pela pesquisa, duas utilizaram artigos como fontes e apenas uma é oriunda de uma agência de produção de conteúdo, a Abril Branded Content.

Gráfico 7: Origem das fontes usadas nas matérias de janeiro

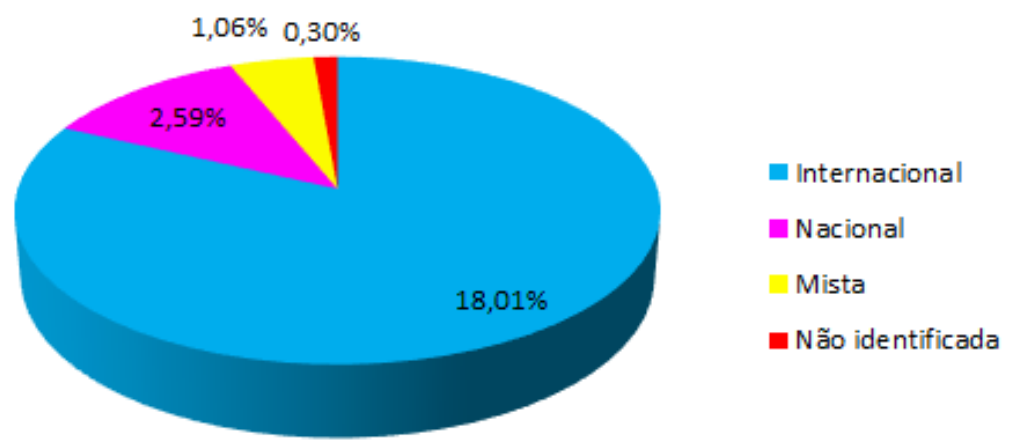

Em fevereiro (Gráfico 8) foram 129 (19,69\%) matérias de origem internacional, 16 $(2,44 \%)$ de origem nacional, $11(1,67 \%)$ mistas e quatro $(0,61 \%)$ sem fontes definidas. Com relação às notícias de origem nacional, sete têm como fonte o(s) pesquisador(es) responsáveis pelo estudo, sete utilizaram algum site como fonte e apenas duas fizeram uso dos próprios artigos científicos das pesquisas em questão. 


\section{ESTUDOS EM JORNALISMO}

Gráfico 8: Origem das fontes usadas nas matérias de fevereiro

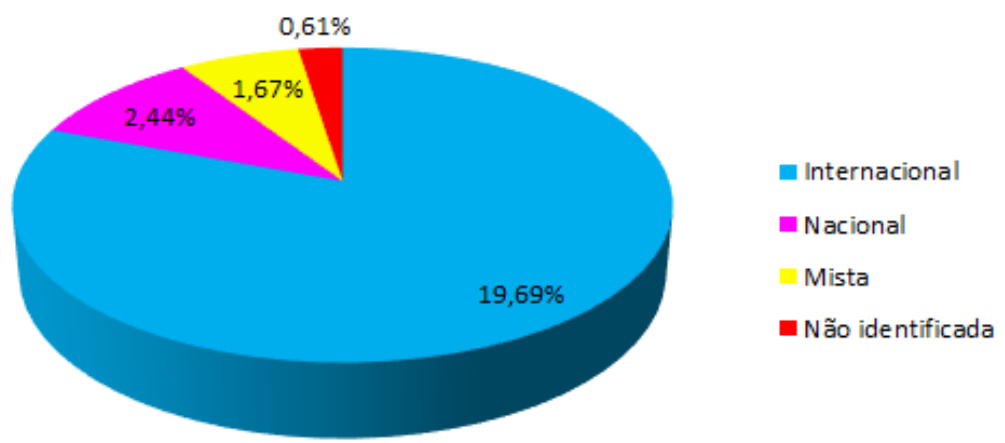

No mês de março (Gráfico 9) 166 (25,34\%) matérias utilizaram fontes internacionais, enquanto somente nove $(1,37 \%)$ matérias eram de origem nacional e oito $(1,22 \%)$ oriundas de parcerias entre universidades nacionais e internacionais. Uma matéria nacional utilizou redes sociais como fontes, três utilizaram responsáveis pela pesquisa e cinco fizeram uso de sites para embasar as matérias.

Gráfico 9: Origem das fontes usadas nas matérias de março

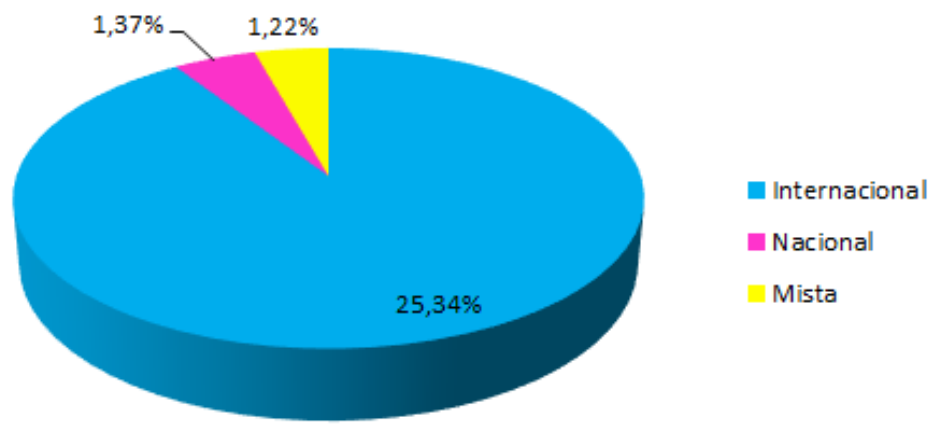

O mês de abril (Gráfico 10) mesmo sendo o mês que produziu o maior número de matérias de origem nacional, $25(3,81 \%)$ no total, ainda ficou atrás do total de pesquisas internacionais $139(21,22 \%)$, possuindo apenas duas $(0,30 \%)$ matérias de fontes mistas. Analisando as fontes nacionais, é possível observar que 19 matérias utilizaram como fonte 
algum pesquisador responsável pelo estudo, cinco utilizaram sites e apenas uma utilizou um artigo científico.

Gráfico 10: Origem das fontes usadas nas matérias de abril

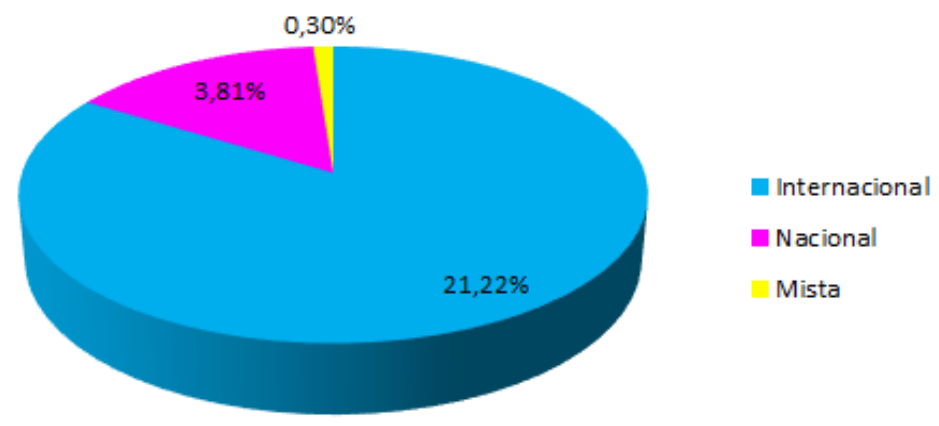

\section{Origem das fontes}

Em 2018, a maioria das matérias no portal da Galileu, da editoria de Ciências, foi publicada pela Redação Galileu, sem identificação de jornalista autor, além de possuir duas estagiárias entre as autoras que mais publicaram matérias de ciência. Durante os quatro meses de análise foi observado que os cinco autores que mais publicaram matérias no portal da revista Galileu foram descritos como: Redação Galileu (343), e os jornalistas Felipe Floresti (21), Larissa Lopes e A.J. Oliveira (13), e Vitória Batistoti (10).

Felipe Floresti é graduado em Jornalismo pela Universidade Metodista de São Paulo e pós-graduado em jornalismo literário pela ABJL. Na ocasião era repórter na revista Galileu. Larissa Lopes era estudante de Jornalismo na Universidade de São Paulo (USP) e estagiária na Editora Globo. André Jorge de Oliveira (A.J. Oliveira) é formado em Jornalismo pela Faculdade Cásper Líbero era repórter na Editora Globo. Vitória Batistoti é formada em Jornalismo pela Universidade de São Paulo e era estagiária na Editora Globo.

Já no portal da Superinteressante, os cinco autores em destaque foram Bruno Vaiano (73), Ana Carolina Leonardi (30), Lucas Baranyi (29), Felipe Sali (21) e Ingrid Luisa (16). Bruno Vaiano se formou pela Escola de Comunicações e Artes da Universidade de São Paulo e na época era repórter científico na Editora Abril. Ana Carolina Leonardi também era repórter na Editora Abril. Lucas Baranyi é formado em Jornalismo pela Faculdade Paulus de Tecnologia e Comunicação e trabalhou como repórter na Editora Abril de maio de 2015 até junho de 2016. Felipe Sali é formado pela ESAMC, trabalhou como jornalista 
freelancer na Editora Abril de abril de 2015 até janeiro de 2016 e atualmente é autônomo. Ingrid Luisa era estudante de Jornalismo na Universidade de São Paulo e estagiária na revista Superinteressante.

\section{Considerações finais}

$\mathrm{Na}$ primeira fase de análises (2016), o portal da revista Superinteressante era gratuito. Desde 2018 possui um sistema de assinaturas que restringe o acesso a apenas cinco matérias por mês, enquanto o portal da Galileu continua gratuito e conta com uma grande quantidade de notícias publicadas diariamente. Em 2018, na análise realizada na editoria Saúde, a Superinteressante publicou mais matérias do que a Galileu, com um total de $50(76,92 \%)$ e $15(23,07 \%)$ matérias respectivamente, enquanto na análise da editoria Ciências o resultado foi o oposto: 431 (65,8\%) matérias de autoria da Galileu e 224 (34,1\%) da Superinteressante.

Resultados parciais da pesquisa mostram que, durante o período estudado, a maioria das fontes de informação utilizadas nas matérias de ambos os portais são provenientes de sites de entidades internacionais renomadas do mundo da ciência, como revistas científicas e sites.

Considerando os dois veículos de informação em 2016, (87,69\%) das matérias são provenientes de pesquisas internacionais, $(10,76 \%)$ nacionais e $(1,53 \%)$ mistas, ou seja, oriundas de parceria entre duas ou mais universidades brasileiras e estrangeiras. Durante o período de quatro meses em 2018, foi identificado que, novamente, a maioria das matérias $(84,27 \%)$ publicadas em ambos os portais das revistas Superinteressante e Galileu têm como fontes pesquisas internacionais, (10,22\%) utilizaram fontes nacionais e $(4,27 \%)$ mistas.

O presente artigo apresenta a primeira etapa da pesquisa, com dados da coleta de nas revistas já citadas. Para análises complementares, estudos de noticiabilidade indicam critérios utilizados por jornalistas e editores, encontrados "no tratamento dos fatos, centrados na seleção hierárquica dos fatos e na produção da notícia, desde condições organizacionais e materiais até cultura profissional e relação jornalista-fonte e jornalistareceptor" (SILVA, 2005, p. 95)

A opção pelas fontes internacionais pode estar relacionada à credibilidade das instituições que divulgaram a pesquisa, no caso revistas científicas de prestígio, universidades e centros de pesquisa internacionais (BONANNO, 2015). O que faz com que 
os periódicos estrangeiros sejam mais utilizados. "Recebemos pauta do Eureka alert, com data de embargo, tudo certinho. Nas pesquisas nacionais isso não acontece. (...) Como ninguém fica sabendo de muita coisa, quem descobre acaba dando como furo" (p.118). No Brasil, há claramente uma dificuldade no acesso às pesquisas nas universidades. "Cada vez mais, a gente tem as informações à disposição. Acho até que os pesquisadores brasileiros estão mais dispostos. Há alguns anos, era mais fácil falar com pesquisador estrangeiro do que brasileiro" (p. 65).

Por outro lado, tais resultados indicam que indica a subutilização de fontes nacionais, provenientes de institutos de pesquisa, universidades, bem como da produção científica realizada em congressos e na publicação de artigos. Dados mostram que a produção de pesquisa nacional está em primeiro lugar na América Latina e em $23^{\circ}$ no ranking global (NATURE INDEX, 2018). Dentre as razões desse fato, podem incluir como hipóteses iniciais, a formação deficitária de jornalistas na área de jornalismo científico, a divulgação insuficiente da pesquisa nacional e a dificuldade de acesso às fontes nacionais.

\section{Referências}

ALBAGLI, S. Divulgação Científica: Informação Científica Para a Cidadania? Ciência da Informação, v. 25, n. 3, p. 396-404, 1996.

BONANNO, Lucas Pondaco. BONANNO, Lucas Pondaco. Os bastidores do jornalismo científico: critérios de noticiabilidade que determinam a circulação da informação à sociedade [doi:10.11606/D.6.2015.tde-02062015-101519]. São Paulo: Faculdade de Saúde Pública, Universidade de São Paulo, 2015. Dissertação de Mestrado em Saúde Materno Infantil.

BUCCHI, M.; TRENCH, B. Routledge Handbook of Public Communication of Science and Technology. Routledge, 2014. Disponível em:

<https://books.google.com.br/books?hl=en\&lr=lang_en|lang_pt\&id=ArHcAwAAQBAJ\&oi=f nd\&pg=PA27\&dq=scientific+journalism\&ots=2BfHvnmSWK\&sig=YELGzQzAXG9TFoS9rd 2oFpALW0s\#v=onepage\&q\&f=false $>$. Acesso em 23 fev 2018.

BUENO, W.C. Comunicação científica e divulgação científica: Aproximações e rupturas conceituais. Londrina, v. 15, n. esp, p.1 - 12, 2010. Disponível em: <http://www.uel.br/revistas/uel/index.php/informacao/article/view/6585>. Acesso em 3 nov 2017.

FARIA, G. A; LOPES, G. Z. L. Fontes de informação em notícias de saúde: uma busca em portais de revistas de divulgação científica. Anais. In: XXIII Congresso de Ciências da 
Comunicação na Região Sudeste, 2018, Belo Horizonte. XXIII CONGRESSO DE CIÊNCIAS DA COMUNICAÇÃO NA REGIÃO SUDESTE. Belo Horizonte: Fumec, 2018.

FARIA, G. A.; ZAUITH, G. A pesquisa internacional como fonte de notícias de saúde: uma busca em portais de revistas de divulgação científica. In: Simpósio Internacional de Iniciação Científica e Tecnológica da USP, 2016, Ribeirão Preto. Simpósio Internacional de Iniciação Científica e Tecnológica da USP, 2016a.

FARIA, G. A; LOPES, G. Z. L. A pesquisa internacional como fonte de notícias de saúde: uma busca em portais de revistas de divulgação científica. Anais. In: X Encontro de Iniciação Científica do Centro Universitário Barão de Mauá, 2016, Ribeirão Preto. Encontro de Iniciação Científica do Centro Universitário Barão de Mau, 2016b.

GIL, A C. Como elaborar projetos de pesquisa. 4.ed. São Paulo: Atlas, 2002.

MACHADO, E. O ciberespaço como fonte para os jornalistas. Salvador: Calandra, 2003. Disponível em: <http://www.bocc.ubi.pt/pag/machado-elias-ciberespacojornalistas.pdf> Acesso em: 1 mai 2018.

NATURE INDEX. 2018 tables: countries. Disponível em: <https://www.natureindex.com/annual-tables/2018/country/all>. Acesso em: 7 Fev 2019.

NATURE INDEX. 2018 tables: territories. Disponível em:

<https://www.natureindex.com/annual-tables/2018/country/all/regions-South\%20America>. Acesso em: 7 Fev 2019.

OLIVEIRA, F. Jornalismo científico. São Paulo: Contexto, 2005.

SILVA, G. Para pensar critérios de noticiabilidade. Estudos em Jornalismo e Mídia, Vol.II № 1 - 1은 Semestre de 2005.

Recebido em: 08/03/2019.

Publicado em: 23/07/2019.

Revista Pauta Geral-Estudos em Jornalismo, Ponta Grossa, vol. 6, n. 1, p. 148-165, Jan/Jun, 2019. 